\title{
Instructional Leadership and School Climate a Case Study of a Secondary School in Eritrea
}

\author{
Berhane Aradom Tedla \\ School of Education, Northeast Normal University, China
}

\begin{abstract}
A school principal has a unique and diverse set of responsibilities that includes, among other things, leadership, and this could range from transactional to transformational leadership. This case study conducted in a secondary school to explore the Role of Principal as an Instructional Leader in Creating a Quality Learning Atmosphere. In this study, the principal was selected purposefully and interviewed, and 25teachers were randomly selected to fill openended and closed ended questionnaires. Hence, the study employed qualitative and quantitative modes of data. The study is relevant to the newly introduced curriculum, called 'Student-Centered and Interactive Pedagogy' in Eritrea, which requires effective instructional leaders. The study relies on a conceptual framework and Bossert's Model that is strongly based on the theory and practice of instructional leadership. In the study, it was discovered that the principal's time is consumed by other tasks rather than instructional leadership. Besides, there is limited teacher participation instructional leadership and little family and community involvement in the school wide issues. In effect, there is a low cooperation, collaboration and communication between the school and communities. The findings highlight the importance of a shared instructional leadership as a best way to utilize human potential and promote staff development programs.
\end{abstract}

\section{Introduction}

Schools struggle and endeavor continuously to create a conducive learning environment for high learning performance and outcome, academic excellence and success. Nonetheless, at the end, these high expectations and continuous efforts will be marked as high performance or low performance in terms of outcomes attained by the learners at the end of every year. It's such labeling that triggered and inspired the undertaking of this case study in a secondary school in Eritrea. The aim was to find out the contributing factors and conditions that underlie the high or low performance of a school. Of course, there are social and contextual factors that facilitate or hinder the performance of a school, such as the socio-economic conditions of students, organizational culture of the school, school leadership, teacher's motivation and other elements. All these have considerable and far reaching effects upon the achievements of students at the end of a year. But, this study concentrated specifically on the role of the principal as an instructional leader in facilitating a quality learning environment by defining the mission of a school, coordinating staff development programs, supervising and evaluating teachers, parents and community involvement, sharing of instructional leadership and collaborating among staffs. The principal as an instructional leader is an actor and has a pivotal role to influence and improve the teaching-learning process. In effect, a school could function productively, enjoy and experience a high level of students' performance and teachers' commitment. As previously conducted researches show, a principal as an instructional leader has a fundamental role and far reaching effects in the effectiveness of a school's performance in general and instructional processes in particular.

In 2005, Eritrea's National Department of Education introduced a new curriculum called 'Student Centered and Interactive Pedagogy', but it still remains to be seen how principals will work, create comfortable school climate and provide assistance to teachers and all other stakeholders within a school. Any school expects a principal to create a quality learning atmosphere for all its stakeholders who are within a school and interested community members to participate.

Instructional leaders have complex multidimensional tasks. If instructional leaders believe that academic growth in students' lives is the primary goal of their school, then it is worth creating a quality learning atmosphere. In today's rapidly changing world, instructional leaders should become leaders of leaders by working and learning with school stakeholders, such as teachers, students, and parents in order to improve implementation of instructional quality, mission and 
goal setting, communication, problem solving, shared instructional leadership, staff coordination and development programs, supervision and evaluation, and collaboration among stakeholders .

The role of a principal has become dramatically more complex, overloaded, and unclear over the past decades. Indeed, the role of a principal as an instructional leader is highly important and complex in nature and it is in a state of continuous transformation, shifting and progressing from a principal as an instructional leader or master teacher, to a principal as a transactional leader and, most recently, to the role of transformational leader[1].

Numerous literatures have precisely and concisely showed the importance of the role of a principal as an instructional leader to improve and promote a quality learning and teaching through a shared and collaborative instructional leadership [2, 3, 1].

A principal as instructional leader is an iconic figure; however, as research clearly indicates, most principal's time is wasted on other duties rather than spent on instructional tasks and roles. It was calculated that $62.2 \%$ of the principal's time is preoccupied on school management related issues; $6.2 \%$ of their time is directed and focused on program issues, such as monthly and yearly plans of a school. Similarly, a principal executes a lot of tasks and functions each day, but from the numerous tasks only $11 \%$ are related to the role of instructional leadership [4].

A common and visible complaint from principals is that, although they would like to spend much of their time on instruction related issues, such as teaching, learning, professional staff development, curriculum development and implementation, and instructional leadership, their time is so exhausted with things like paperwork, phone calls, and student discipline referrals. In the end, they simply don't have time to deal with instructional leadership tasks that most directly and deeply impact teaching and learning [5]. However, it is proposed that if schools are to improve and progress smoothly and properly, the school principal should not let other daily duties intermeddle with the main instructional leadership role in curriculum implementation [2]. It is true that principals are overloaded with roles and responsibilities, but there are many stakeholders within the school who can carry the burdens, if the principal promotes cooperation and shares instructional leadership with them.

The research question that guides this study is, Is a School Principal as an Instructional Leader creates a quality learning atmosphere or not? To answer this research question the following instruments were used: 1. What does it mean to be by an instructional leader? 2. How does a School Principal as an Instructional Leader spend his/her time?
3. How does the principal produce and shape a school culture of learning, and provide an intellectual stimulation?

The purpose of this case study is directed towards exploring a Principal's Role in Creating a Quality Learning Atmosphere and to identify and investigate what practices of a principal would promote and support a quality learning atmosphere.

\section{Literature Review}

Instructional leadership is defined differently by different scholars and researchers. Researchers and scholars acknowledge that there is no single clear definition of instructional leadership or specific guideline as to what a principal as an instructional leader does in a school. They build up their own definitions, and as a result of this, meanings vary considerably from one researcher or practitioner to another. This lack of clarity and consistency in definition has resulted in part of the problem [3]. Road signs exist, but no maps are yet available for sale [6].

Instructional leadership is defined as the role that is taken by a principal in a school to execute an effective instruction by creating a quality and favorable climate $[7,8]$. It is also defined narrowly as a task that focuses on leadership functions directly related to the teaching and learning process; whereas in a broader view it is a function that contributes to student learning, including managerial behaviors [8]. Instructional leadership consists of those actions that a particular principal takes and delegates to others in order to promote growth in student learning [9].

\subsection{Effective Principal as an Instructional Leader}

Effective principals are expected to create and facilitate a conducive teaching and learning environment. This implies that a principal must be knowledgeable about instructional effectiveness and staff development [10]. Some researchers endorse the holistic view of the principal's role as an instructional leader $[11,1]$. The holistic definition and concept of instructional leadership and management is to be an active, collaborative form of leadership where the principal struggles and works hard with and among teachers to shape and build the school as a workplace pertinent to shared goals, teacher collaboration, teacher learning opportunities, teacher certainty, teacher commitment, and student learning[1].

An effective instructional leadership is defined as setting and creating an environment of great expectations for all stakeholders and learners, 
promoting collegial and collaborative relationships among educators and creating a commitment among staff and students toward a school's goals, facilitating and encouraging teachers to spend their time on direct instruction, encouraging staff development programs, supervision and evaluation, and being a dynamic and educative leader [12]. It is maintained that an effective principal invests in teachers with necessary resources and instructions [13], and in the meantime a principal maintains a congruence and consistency of the educational program [14].

Seven steps have been identified for an effective instructional leadership, such as establishing clear instructional goals, being resourceful for staff, creating a school culture and climate conducive to learning, communicating the vision and mission of the school, setting high expectations for staff, developing teacher leaders, maintaining positive attitudes toward students, staff, and parents [15].

Unlike the conventional notion of instructional leadership, sharing instructional leadership is an inclusive concept that is compatible with competent and empowered teachers [16]. Teachers' participation and involvement in shared instructional leadership takes place both formally and informally as teachers assume more leadership responsibility when they interact with other stakeholders and adults in the school community. They implement reforms to improve their professional practice, or learn together with their school colleagues collaboratively [17].It is also perceived that the role of the principal as an instructional leader, in models of the future, will be encouraging a collaborative atmosphere for teachers to play a central role in the effectiveness or improvement of a school [1]. This requires an active pivotal role of the principal to facilitate a conducive environment by motivating the staff and students through reaching out to the community, and continually improving and changing the school [18]. However, school management and instructional leadership are two different and distinct tasks that cannot be performed or done at a time by a single individual. It is a strongly agreed that teacher empowerment, in which teachers have significant input and contribution into decisions concerning instruction, is indispensable. Moreover, others argue that well-managed schools enable real instructional leaders to empower teachers who can create the effective school reforms they are seeking [19].

\subsection{Conceptualizations and Model of Instructional Leadership}

The past 25 years have witnessed the emergence of new conceptual models in the field of educational leadership. However, two of the foremost models that are measured by the number of empirical studies, are instructional leadership and transformational leadership [20]. Instructional leadership models have appeared in the early 1980s based from early conducted research on several effective schools [21]. These bodies of researches clearly identified strong and directive leadership focused on curriculum and instruction from the principal as a characteristic of elementary schools that were effective at teaching children in poor urban communities. With the advent of school restructuring in North America during the 1990s, scholars, researcher and practitioners have begun to popularize leadership terms, such as shared leadership, teacher leadership, distributed leadership, and transformational leadership [20]. The appearance of these leadership terms or models vividly indicated that a broader dissatisfaction with the existing instructional leadership model, which many believed that too much focus on a principal as the centre of expertise, power and authority. Although there are different of conceptual models, over the past 25 years of research into area of educational leadership, two major approaches have predominated greatly, such as instructional leadership and transformational leadership. Studies starting from the early to late 1980s were dominated by an instructional leadership conceptualization, which are drawn from effective schools literature.

For the purpose of this research study, Bossert's Model of 1982 was used to show the principal's influence on school climate, instructional organization and student achievement. According to this model, the principal's managerial behavior is shaped by school context and personal characteristics, and in turn the principal directly affects the school and instructional organization, and indirectly influences school performance (student achievement).

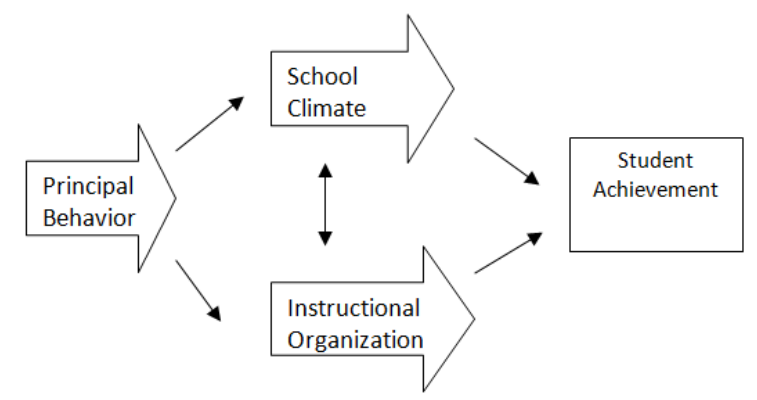

Bossert’s Model, 1982

This model of instructional leadership provides a spotlight for the improvement of instructional quality, such as learning, teaching and working collaboratively with staffs, students, parents, communities and 
interested groups. It's however the responsibility of a principal to create a strong school culture and climate that assists staffs to collaborate and redesign an instructional program.

The role of a principal as an instructional leader, in models of the future, will be encouraging a collaborative atmosphere for teachers to play a central role in the effectiveness or improvement of a school culture. However, it will require active and pivotal role of the principal to facilitate a conducive environment by motivating staffs and students through reaching out the community, and continually improving and changing the school (Fullan, 1991).

\section{Data Presentation, Description and Interpretation}

\subsection{Research findings}

Table-1: Teachers' Profile

\begin{tabular}{|l|l|}
\hline Gender & $\begin{array}{l}\text { Male=21 } \\
\text { Female=4 }\end{array}$ \\
\hline Qualification & $\begin{array}{l}\text { Diploma=3, } \\
\text { MA/MSC=0 }\end{array}$ \\
\hline Teaching & $0-5=7$ \\
experience in & $5-10=8$ \\
years & $10-15=5$ \\
& $15-20=9$ \\
& $20-25=2$ \\
& $25-30=1$ \\
\hline $\begin{array}{l}\text { Leadership } \\
\text { experience(No } \\
\text { of teachers in }\end{array}$ & As Department Head=5 \\
leadership & As Principal=2 \\
position) & As School administration=0 \\
\hline
\end{tabular}

The school principal in the case study has seven years of experience in a leadership position, taught for fifteen years before became a principal, and currently, he teaches a class every day. He was trained as a teacher, not as a leader of a school. He learned leadership on the job by trial and error. He reported that he did not even take a workshop or any form of leadership training. He further reported that it's a problematic issue to experiment leadership on the real ground without an initial learning at least theoretically, for it took me a long journey to explore and understand the scope of principalship. Sometimes, roles and responsibilities go out beyond and out of control, and don't know how to deal with it and get the assistance of staffs. However, through time, I've learned somehow to comprehend the nature and scope of leadership and make division of labor among teachers by empowering. The principal also indicated that early in the beginning of my career as a principal, most of time was scattered and suspended to every detail of what happened within the school. However, the principal added, currently most of my time is consumed in managerial tasks, planning, office works, paperwork, student discipline, budget, seminars and the like that I does not have adequate time to deal with instructional tasks.

The principal showed that the school functions as per preset guidelines and philosophy. The mission of the school falls under the umbrella of the Ministry of Education (MOE), and executes the imposed curriculum developed by the Department of National Curriculum. Though the curriculum developed without teachers' participation, it was piloted in a school before actual implementation. However, the implementation process remains problematic and uncertain, for it requires high number of teachers and expertise, and democratic school leadership. In Eritrea, teachers were/are trained in the approach of teacher centered methodology, not as student centered and interactive pedagogy. Besides, school leadership is at an infant or immature stage. Principals are experienced teachers, not experienced leaders. It takes them a tremendous amount of time to learn on the job and become real school leaders. This made the newly introduced curriculum impractical.

For the past twenty years, the state of Eritrea in general and Ministry of Education in particular, have made a lot of amendments and brought fundamental changes to thrive the educational philosophy and system. In the entire country a number of schools built, infrastructure changed and students' enrollment increased, but still the school leadership remains unchanged and a problematic.

The principal in the case study reported that almost everything in Eritrean schools is changed, but the nature leadership is yet unknown and principals take leadership responsibility as personal power to exercise fear and create threats. Principals don't understand instructional leadership as a role to promote an effective teachinglearning process, the principal added. Besides, the principal explained that in the ordinary sense, true principalship endorses the sharing of instructional leadership, collaboration, promotes staff development programs and calls for an immediate involvement of parents and community members, but in reality it's hard to make it happen.

Truly understood and effective instructional leadership is very important as an engine to mobilize teachers to teach wholeheartedly, motivate students to explore and learn, and community members to involve and become important agents in a school. The aspiration to coach and participate families and communities, and the motivation to mobilize and utilize the resources of a school are the outcome of visionary instructional leadership. 
A school is an organ that receives inputs, undergoes processes and ultimately pumps byproducts as outs of inputs. A principal as a model of learning and central figure of change, need to consider his school as an organism of potential scientists, philosophers and leaders, not as an organizational structure of bureaucratic administration and management . The participants clearly indicated that real school culture is not the outcome clever technique, but of a school leadership that treats a school as a place of human realization. The mission statement of the Ministry of Education supports these findings, but practically the school employs old fashioned practices that don't support the ideal development of cognitive, social and motor skills of students. Besides, a school as an organism should constitute home, family and communities, but the study revealed that there is a limited of these entities in the school wide decisions that pushes an increased students' drop out and teacher absenteeism.

In the modern education system, school-community relations are very important and have far reaching effects to students' achievements. The principal reported that he endorses a friendly climate to work collaboratively with teachers and shares instructional leadership authority that perhaps helps to create a quality learning atmosphere and ensures an academic excellence. However, $75 \%$ of the sample teachers reported that the principal does not share instructional leadership as it should be. One unique respondent from the teachers reported "real teacher motivation is not an outcome of salary, but outcome of a conducive work environment resulting from a shared instructional leadership, visionary mission and collaboration". Teachers feel a sense of ownership and responsibility when the right environment is in place, they added.

The sample teachers are bored and switched off by the existing school leadership and could not think outside of their classroom. Their participation in improving instructional leaderships doesn't exist at all. Some teachers from the sample study which is $35 \%$, take personal power, initiative, influence and interest to be involved in decision making processes, students' discipline matters, and warmly invite parents so as to participate in disciplinary matters and academic progress of their children; this in turn helps parents to become familiar with the school leadership, mission and culture. It was also revealed that the principal is not democratic enough to empower teachers that perhaps will help them to participate in the decision-making process of the school. With increased teacher involvement, school decisions become an effective tool for focusing on both the staff's and students' needs and outcomes [22]. True principals capture good attitude and cultivate the spirit of their teachers and ultimately empower them to influence the school climate and improve instructional effectiveness.

The case study discovered that the school does not provide all the necessary resources to teachers and students. The school lacks the adequate teaching aids, textbooks, laboratory equipment, computer laboratory, free internet café, a library with adequate supplementary books, and other related instructional materials. Providing the resources that are needed for learning to occur is one of the main tasks of instructional leadership. It's a treasured task that a principal as an instructional leader should make resources available and allocate wisely and effectively [23].

The research further revealed that the school provides little professional development to teachers, school administrators, and the deputy principal that focus on increasing their potential, personal competency and ability to recognize that enables them to foster an excellent teaching and learning atmosphere. Most professional development programs are conducted at a national level by the Ministry of Education.

Coordinating staff development programs is the main role and function of a principal as an instructional leader in facilitating a quality learning atmosphere [22]. The principal explained that a principal alone could not carry the issue of staff development program. School administrators and assistant principals should understand the integral roles of professional development in the operation of the school and organize them around teaching-learning processes that in turn will help and provide teachers and other staff the opportunities to upgrade their profession in their respective areas, the principal insisted. Furthermore, the principal explained that on a monthly basis the school calls teachers and other staffs for a meeting/seminar in order to evaluate the past achievements and understand the status quo of the school, then accordingly to plan ahead for the coming academic year. In so doing, the principal explained, the school stakeholders, particularly teachers, feel a sense of ownership, belongingness, and become passionate to explore and update their profession. In addition to this, the principal reported that the school seeks a collaboration and new partnership with other schools, colleges and universities for the sake of staff development programs. However, it's not yet happened in reality; it demands a lot of efforts to make it happen.

The principal claims that teacher supervision and evaluation is one of the best ways to enhance and upgrade teacher profession. The main focus is to utilize teachers' potential, and in turn maximizes students' learning and achievement. Teacher supervision and evaluation enables a school to maintain standards and make check and balance. The principal employs natural observation and scheduled supervision as a critical 
aspect of evaluation. However, the principal explained, to undertake this role effectively it's necessary that a principal should have a thorough knowledge of supervision, mastery of the subject matter and a checklist of evaluation form that corresponds the objectives of instruction. Knowing when and how to supervise and under what circumstance is very problematic for school principals, he explained.

The principal reported that the newly introduced curriculum requires an inclusive leadership, high level of coordination, effective supervision and evaluation because it is introduced on the basis of student-centered and interactive pedagogy. Sometimes teachers have a hard time in organizing and handling interactive discussions within the class as the teacher-student ratio ranges from 1:50 to 1:70. Because of this, he added, it's a policy of the school to observe naturally, randomly and intentionally (scheduled) to conduct teacher supervision and evaluation. The school after supervision and evaluation briefs teachers in a friendly manner their strength and weaknesses based on the newly introduced curriculum. In effect, this helps to foster effective teaching, and above all, ensures teachers' confidence, competence, capacity, flexibility, collaboration, and independence. Furthermore, the principal stressed that teacher evaluation process is based on the belief that the nature of teaching profession is dynamic as well as a continual process. The teacher evaluation plan emphasizes the relationship between teaching and learning, and school improvement and leadership.

In this paper, it's discovered that effective instructional leadership is indispensable for a school climate and improvements, among which the following are worth mentioning:

- Planning and preparation: After supervision and evaluation, teachers plan and prepare wisely to ensure the desired expectations are met for all students. It helps to avoid delaying of curriculum implementation.

- The classroom environment: Teachers become more responsible and know how to build an effective classroom atmosphere. This is one of the most problematic and critical issues for some teachers to make it happen. More than anything, a quality learning atmosphere matters a lot more than other school factors.

- Instruction: Through continuous supervision and evaluation, teachers have come to know, learn and work hard to master the subject matter. Not only content-wise, but also pedagogical knowledge.

- Monitoring Student Achievement: a wise and effective supervision and evaluation of teachers by a principal in turn produces a good student evaluation by teachers.

- Professional Responsibilities: Eventually as an aggregate outcome, teachers think rationally and critically about their profession, practices and learning experiences. In effect, they start to work collaboratively and create collegiality in the learning community of a school and outside it.

\subsection{Summary, Discussion and Conclusion}

The findings reveal that the principal as an instructional leader does not provide an adequate conducive climate for teaching and learning process, but he recognizes the importance of collaboration and sharing instructional leadership. The climate of collaboration and sharing instructional leadership boost teachers' spirit. This in turn provides the students with the condition of effective learning and high achievement. However, the role of principal as an instructional leader remains only as a role rather than a function, and it was also discovered that the principal has not been trained as a principal, but as a teacher only. This negatively affects the concept of teacher leadership, and parent and community participation as a way of school effectiveness and improvement. Furthermore, it's discovered that the principal consumes most of his time dealing with managerial issues, meetings, paperwork, planning, budgeting, student discipline, and office tasks that the principal does not have adequate time to deal with instructional processes. In the mean time, it was also revealed that empirical research is important for the role of principal as an instructional leader in order to promote and embrace visionary school leadership in Eritrean context. Ideally, the role of principle would foster participative, collaborative and shared instructional leadership among teachers. These concepts are crucial for the teaching and learning processes, teacher satisfaction, and for high student achievement. In the case study, it was discovered that there is lack of teacher readiness, inaccessibility of adequate resources, limited participation, and lack of teachers' in-service training. This implies that there is no a conducive environment for the teaching-learning process to be effectively implemented. A principal as a pivotal figure has a powerful impact over the whole school culture to utilize both human and material resources wisely or effectively. The study covers a number of researchers' findings, ideas and thoughts, but most of them indicate the right atmosphere that a principal should create and maintain an academic excellence. Hence, a principal's 
leadership attitude is indispensable in assuring the right teaching-learning atmosphere.

The synthesis of literature reviews, interviews, and questionnaires further point out the importance of a principal as being an instructional leader. By far that would lead to improvements in the school environment and culture. A principal as an instructional leader is a central in the promotion of a climate of effective teaching-learning process through the seven steps that were identified by McEwan. The seven steps are establishment of clear instructional goals, be resourceful for your staff, create a school culture and climate of conducive to learning, communicate the vision and mission of a school, set high expectations for the staff, develop teacher leaders, and finally, to maintain a positive attitude towards students, staff members, and parents.

The participants reported that the newly introduced curriculum (student-centered and interactive pedagogy) is not easy to be implemented and far from clarity; it's ambiguous. It requires a high human expertise, teacher participation and large amount of instructional resources. In the first place, they reported, "we are not familiar with it because it's an imposed curriculum from top to bottom by the Ministry of Education; and also the teachers have not yet trained based on the newly introduced curriculum and lacks the necessary orientation. The principal, they added, struggles very hard to create an instructional atmosphere, but lacks a culture of leadership share with school stakeholders. In the case study, it's discovered that there is a limited participation of teachers and students in a school wide decisions and absence of parent and community involvement in the school governance.

The school is over managed and administered, but it's led very little. In the case study, the principal is a good driver based on the existing practices. Naturally, human being can drive a car, but cannot drive schools, for schools are organisms, not organizations. True principals are leaders and risk takers to change old practices and innovate practices. Change is inevitable, but it becomes a dynamic process, if it's done intentionally.

Principals are the central figures of change and leaders of leaders within their kingdom. They distribute leadership far wide to empower staffs and invite parents and community members as main elements of their schools. It's a conventional wisdom that a principal as an instructional leader cannot happen a work done alone without the assistance, ideas and cooperation of other staffs. As an instructional leader, a principal need to set a tone that powerfully impacts a quality learning atmosphere of a school culture. This could happen merely through sharing instructional leadership that enables teachers and educators to cooperate, collaborate, communicate harmoniously heart to heart and walk shoulder to shoulder. In turn, this will help both the principal and his subjects to think the talk, talk the talk and eventually walk the talk.

The case study, one way or other way, indicates that a principal as a leader need to be a thermostat to regulate the school climate and thermometer to measure achievements and how far the school moves. This concept implies that a principal as a learning catalysts, social engineer and architect, and moral agent.

School life is the overall culture that reflects as:

- to the degree where students and teachers are motivated,

- the approach in which stakeholders are communicated, cooperated, involved or participated

- The culture in which educators are related to one another

- The overall perception towards teachinglearning process

- Punctuality of stakeholders

- The approach of discipline

- The lack of teachers' absenteeism

- The reducing of students drop-out

- The atmosphere whether staff development is supported

It can be concluded that a principal as an instructional leader need to be a visionary, purpose founded, a bedrock of school culture, a corner stone of leadership, changing agent, participative leader, mould a culture of learning, initiator of uncommon ideas, a cause of transformation, a wise risk taker, magnetic personality, a solid bridge to the future, source of empowerment, information and resources, and easily available to everyone. Leadership is not a position, good office or title, but it's a choice to serve others and promote human development. The conventional definition of leadership is to motivate, inspire and utilize both human and material resources. However, this should be as a cost of human choice and service. The moral of this idea is that a leader should choose and seek to service humanity, not to a position.

Nowadays, school principals are diverted from the main track of leadership service to other issues that impede the prosperities of academic excellence. Many principals as instructional leaders are notable figures or models of academic excellence. However, overwhelmed by managerial activities that are scattered around many different issues, such as management, planning, administration, politics, and spending a lot of time in meetings, phone calls and discipline matters that destruct the smooth running of instruction. 
In the case study, it was revealed that only one fourth of the principal's time is invested into instruction related activities; all the rest of his time is consumed to none instructional tasks. His time and energy to improve instructional tasks is stolen. In addition to this problem, the principal doesn't have a culture of empowerment and sharing of instructional leadership with his immediate subjects. The teachers are only restricts within the box of a classroom. One mathematics teacher reported that I'm always between my class and home. The participant said this to indicate the lack of participation in other school activities. Furthermore, one unique participant put it forward this way, "it's not an excuse for a principal to say that my time is consumed by other non instructional tasks, for there are a number of teachers who can handle, if the school shares instructional leadership.

Instructional leadership is wide in scope, complex in nature and inclusive in essence. It's the function of a principal, but the function of everyone within and outside of a school. As a matter of this, Instructional leaders have complex multidimensional tasks. If principals as instructional leaders certainly believe that academic growth in students' life is the ultimate goal of their school mission, then it is a task worth building up a quality and comfortable learning atmosphere for all stakeholders. Effective principals build a leadership capacity that enables staffs to empower, participate in school wide decisions, involvement in curriculum development, create knowledge and combine moral purpose. In today's rapidly changing world, instructional leaders need to be leaders of leader to improve instructional quality by working, innovating, discovering and learning with school stakeholders.

\subsection{Implications for Practice}

A principal maintain a healthy and positive school climate through honesty and open communication, tolerance of different ideas,, modeling a proper human relations skills, building up and uphold high morale, and acknowledging the accomplishment of others [15]. One unique participant reported that for a conducive learning environment to occur, a principal should define and communicate school mission and goals clearly, establish high instructional expectation and standards, be resourceful (information, access, material), foster atmosphere of learning, have a thorough knowledge about instruction and curriculum, coordination of staff development program, evaluate instruction and most importantly should share and promote collaboration leadership.
An effective Instructional Leadership is an inclusive concept in nature that a school principal shares leadership responsibilities with school stakeholders so as to create a climate of learning and play a significant role in implementing an effective instruction. This implies that leadership is not a role of one person, but a function of stakeholders, such as teachers, educators, students, parents and community members. Inclusive leadership assures a conducive learning atmosphere and endorses the participation of all individuals.

Inclusive and shared Instructional Leadership and

Collaboration at workplace creates an environment of:

- Moral and intellectual development

- Participation and involvement of parents and communities governance in a school

- A high teacher motivation and student achievement

- A democratic school that turns into a real progressive rather than oppressive

- A collective instructional leadership, consultative and collegial management

- A professional capacity building

- School base management

Indeed, the role of the principal as an instructional leader is paradox in implementation, highly variable in definition, complex in reshaping schools as organisms rather than structural organizations, and important in producing promising scientists. Principalship is always evolving that's in a state of continuous transformation, shifting and progressing from principal as an instructional leader or master teacher, to a principal as a transactional leader and, most recently, to the role of transformational and dynamic leader.

\subsection{Recommendation}

The case study reveals and highlights the reality within the school. Though, it's limited in scope, it put forwards some important points for improvement. In the study, the principal functions within a limit of traditional box and centralized instructional leadership. It's hard for a principal to question critically and change the accepted old and out of date practices. As of a matter of fact, the researcher categories the recommends part as two: specific and general recommendations.

The specific recommendation directly reflects the research findings, whereas the general recommendations help principals to understand the fundamental principles of school existence, culture and leadership, and ultimately to become universal leaders.

\subsubsection{Specific Recommendations}


Based on the findings, the researcher recommends the following instructional roles and responsibilities:

1) Mission is the glue of school culture. It gives a school a living meaning and fresh beginning. Therefore, the school principal as a master of a school should set and define a mission to the school stakeholders.

2) An effective instructional leader is visionary. Well-performing schools are characterized by a visionary principal that sets high expectations and communicates the vision to educator wisely or effectively.

3) In a tri-polar education system, a school, parents, and communities work cooperatively, walk harmoniously and intent purposefully. The participation and involvement of parents and communities has a far-reaching effect in facilitating learning. Therefore, the school principal should pave the path where parents and communities can lend their hands and redesign instructional programs for the sake of academic excellence and high students' achievements.

4) The principal alone cannot cover all the school programs and activities. Instructional leadership is not a role, but a function of considerable subordinates. Hence, it's a worth sharing instructional leadership with other educators. Sharing instructional leadership is not only facilitates a quality learning atmosphere or lessens the load of a principal, but also releases and utilizes the potential educator-leaders and makes them feel a sense of ownership and honor. Therefore, the school principal should share instructional leadership with the stakeholders accordingly.

5) Coordinating staff development programs is one of the most imperative instructional functions that enables teachers to upgrade their existing expertise, help cope with the dynamism modernization and help also bridge staffs to the future. Therefore, the school principal should build up a staff development program to upgrade instructional facilities, refresh the existing knowledge and build up a ground of experience cultivation and harvest within the school.

6) The Ministry of Education as a state head of all schools within the country has the mandate to transform the practices, change the curriculum, update the structure of educational organization and maintain the values and norms along with the philosophy and common vision and mission. Hence, the Ministry of Education should promote school-community relations that enables schools, colleges and Universities to liaise wisely and link harmoniously for a common purpose.

\subsubsection{General Recommendations}

Principals like any leader should be philosophers of their areas, psychologists of their school climate and sociologists of their school culture. The conventional or literary definition of a leadership is to inspire, motivate and utilize resources. However, it's easy said than done. Hence, it's a matter of must for principals to be students of philosophy, psychology and sociology.

As a philosopher a principal should learn the existence of a school and the fundamental truth of leadership capacity, and will explore also the history of education, and generate new ideas on how to deal with instructional tasks in the day to day basis. Principals should go back to read a lot, think critically and learn vastly the classics of literature about philosophy of education and essence of leadership.

As a psychologist a principal should learn on how to deal with human behaviors, feelings and emotions of his subordinates in a school. Teachers and students are unique in their own design and have different motives. The literary definition of a Psychology is a science of mind or soul. Hence, a principal as a psychologist should capture, understand and maintain a healthy mind state within his kingdom of leadership.

As a psychologist, the main function is to motivate and inspire stakeholders in order to tune up situations and regulate a conducive school climate where teachers can teach wholeheartedly, students learn passionately and ultimately achieve the desired goals and missions of a school. In nutshell, a principal as a psychologist acts as a thermostat.

As a sociologist a principal learns the social composition of his school. Nowadays, more than ever schools are becoming diversified and problematic for a school leadership to be inclusive. Teachers and Students come from a different background, beliefs and culture. Hence, a school principal as an instructional leader should understand the composition of his school and learn the importance of diversity to enhance school improvement and effectiveness.

In nutshell, a principal as a philosopher protects students from indoctrination and becomes also student of life to seek the fundamental truth of his school and essence of leadership, and dies to learn, never retires to die. As a psychologist maintains emotional wellness and becomes a counselor, the champion of friendliness, the master of a school climate and captain of developments. And as a sociologist protects social upheaval and conflicts and become the chemist of social composition and the social architect and engineer. 


\section{References}

[1] M.Fullan. The New Meaning of Educational Change. Teachers College Press, New York, 1991.

[2] B.Berlin, J.Kavanagh and K.Jensen. The Principal As Curriculum Leader: expectation vs performance. NASSP Bulletin, 72(509). 1988

[3] B.Flath. The Principal As Instructional Leader. ATA Magazines. 1989.

[4] J.H. Stronge. A Position in Transition? Principal. 67(5), 32-33. 1988.

[5] S.Gordon. Professional Development for School Improvement: empowering learning communities. Pearson Education, Inc. 2004

[6] L. Cuban. The Managerial Imperative and the Practice of Leadership in Schools. Albany, State University of New York Press. 1988

[7] R.Donmoyer and J.G Wagstaff. Principals can be effective managers and instructional leaders. NASSP Bulletin. 1990.

[8] J. Murphy. Principal Instructional Leadership. R.S.Lotto and P.W.Thurston(eds), advances in educational administration: changing perspectives on the school.Vol.1. Greenwich, CT, JAI. 1988.

[9] W.D.Debevoise. Synthesis of Research on the Principal as Instructional Leader. Educational Leadership. 1984.

[10] R. Hanny. Use, but don't abuse, the principles of instructional effectiveness. The clearing House. 1987.

[11] R.Bryce. The Role of School Principal: should principals be plant managers, principal teachers, or leaders of instructional organization? Canada School Executive, 3(4). 1983.

[12] L. Angus. New Leadership and the Possibility of Education Reform. J.Smyth(ed.). London, Falmer Press. 1989.

[13] S. Rosenblum, K. Louis and R. Rossmiller. School Leadership and Teacher Quality of Work Life in Restructuring School. J. Murphy \& K. Louis (Eds). 1994.

[14] D.T. Conley and P. Goldman. Facilitative Leadership: how principals lead without dominating. Eugene, Oregon. 1994.

[15] E.K. McEwan. Ten Traits of Highly Effective Principals: from good to great performance. Thousand Oaks, CA. 2003.

[16] N.A.Prestine. A constructivist view of the knowledge base in educational administration. Symposium presentation at the annual meeting of the American. Educational Research Assosciation. Atlanta, GA. 1993.

[17] G. Moller and M. Katzenmeyer. The Promise of Teacher Leadership. In R.H. 1996.

[18] D. Moorthy. The Canadian Principal of the 90's: Manager or Instructional Leader, or both? Education Canada, 32(2), 8-11. 1992.

[19] M. Highsmith and S. Rallis. The Myth of the Great Principal: questions of school management and instructional leadership. Phi Delta Kappan, 68(4). 1986.

[20] P. Hallinger. Leading Educational Change. Cambridge Journal of Education. 2003

[21] K. Leithwood and. Montgomery. The Role of the Elementary Principal in Program Improvement. Review of Educational Research. 52(3), 309-339. 1982

[22] M. Bernd. Shared Decision Making Requires Effective Instructional Leadership. NASSP Bulletin, 76 (540), 64-69. 1992.

[23] H. Wildy and C. Dimmock. Instructional Leadership in Primary and Secondary Schools in Western Australia. Journal of Educational Administration. 1993. 